\title{
Prognostic Factors of Clinical Outcome after Aneurysmal Clipping in the Aged Patients with Unruptured Intracranial Aneurysms
}

\author{
Min-Woo Son ${ }^{1}$, Jin-Woo Park ${ }^{2}$, Kyung-Jae Park ${ }^{1}$, Shin-Hyuk Kang ${ }^{1}$, Yong-Gu Jung ${ }^{1}$, Jung-Yul Park ${ }^{1}$, \\ Dong-Hyuk Park ${ }^{1}$
}

${ }^{1}$ Department of Neurosurgery, Korea University Medical Center, Anam Hospital, Korea University College of Medicine, Seoul, Korea

${ }^{2}$ Trauma Center, The Armed Forces Capital Hospital, Seongnam, Korea

Received: February 3, 2020

Accepted: February 17, 2020

\section{Corresponding Author:}

Dong-Hyuk Park, M.D., Ph.D.

Department of Neurosurgery,

Korea University Medical Center,

Anam Hospital, Korea University

College of Medicine, 73 Inchonro

Sungbuk-gu, Seoul 02841, Korea

Tel: +82-2-920-5729

Fax: +82-2-929-0629

E-mail: doctorns@korea.com

\section{Objective}

To determine prognostic factors of clinical outcome after surgical clipping in elderly patients 65 years old and over with unruptured intracranial aneurysms (UIAs).

\section{Methods}

A total of 50 patients with UIAs who underwent surgical clipping between January 2006 and December 2016 were included in this study. These patients were divided into two groups according to Glasgow Outcome Scale (GOS) scores: good outcome group (GOS of 5) and poor outcome group (GOS of 1 to 4). Aneurysmal characteristics and clinical outcomes of patients were retrospectively reviewed for both groups.

Results

Among 50 patients, 38 showed good outcome while 12 had poor outcome. A multivariate study revealed that wide aneurysms neck (OR: $3.467, \mathrm{p}=0.023$ ), small width (OR: $0.511, \mathrm{p}=0.048$ ), large aspect ratio (OR: 9.050, $\mathrm{p}=0.007)$, diabetes mellitus (OR: 1.048, $\mathrm{p}=0.023)$, and smoke (OR: 1.091, $\mathrm{p}=0.05$ ) were significantly associated with poor outcome after surgical clipping.

\section{Conclusion}

Wide neck, small width, large aspect ratio, diabetes mellitus, and smoking were found to be independent prognostic factors associated with poor outcome in elderly patients after surgical clipping of aneurysms. Therefore, these factors in elderly patients should be taken into consideration before make a decision on treatment of unruptured aneurysm surgery.

Keywords: Predisposing factors; Unruptured intracranial aneurysms; Clipping; Outcome; Old age 


\section{INTRODUCTION}

Unruptured intracranial aneurysms (UIAs) are commonly diagnosed due to improved imaging techniques. The rupture risk is increased almost linearly with increasing age of patients with intracranial aneurysms ${ }^{6,13}$. The mortality rate due to rupture of aneurysm ranges from $26 \%$ to $45 \%^{1,15}$. Therefore, it is important for neurosurgeons to decide whether to treat UIAs found in elderly patients. Surgical clipping of UIAs is considered to be more invasive than endovascular embolization.

However, some conditions such as middle cerebral artery aneurysms or wide neck aneurysms need surgical clipping rather than endovascular coiling. Clinical outcomes of surgical clipping of UIA would be associated with various patient' and aneurysmal factors. For example, the risk of postoperative complications may be higher in elderly patients than that in younger patients because elderly patients are more likely to have various underlying diseases such as heart disease, renal disease, and cerebrovascular disease than younger patients ${ }^{14,22)}$. However, it is still unclear which factors more affect the clinical outcome after surgical clipping of UIAs among older population. Thus, the objective of this study was to determine prognostic factors of clinical outcome after surgical clipping in elderly patients 65 years old and over with UIAs.

\section{MATERIALS AND METHODS}

\section{Patient selection and inclusion criteria}

A total of fifty patients 65 years old and over with UIAs who underwent surgical neck clipping between January 2006 and December 2016 were included in this study. Patients were excluded if they had any of the following: 1) prior subarachnoid hemorrhage (SAH) and 2) fusiform aneurysm. Clinical outcomes, aneurysmal characteristics (location, size, and morphological characteristics), and patients characteristics (age, sex, and underlying diseases) were evaluated.

\section{Analysis of aneurysmal characteristics}

Aneurysms were classified into the following categories based on location, size, and shape: 1, middle cerebral artery (MCA); 2, anterior communicating artery ( $\mathrm{ACoA})$ including distal anterior cerebral artery; 3, internal carotid artery (ICA); and 4, posterior communicating artery (PCoA). ICA included the location between the cavernous portion of ICA and the internal carotid artery bifurcation. It also included the origin of the anterior choroidal artery, excluding those located at the origin of the posterior communication. There was no clipping case for cavernous ICA, basilar top, or vertebrobasilar artery aneurysm. Aneurysmal factors in- cluded height, neck, and width of aneurysm. These factors were measured through transfemoral cerebral angiography (TFCA) images. The maximum diameter was defined as the longest diameter of UIA. Aspect ratio was the ratio of height to neck.

\section{Analysis of patient factors}

The following factors of patients over 65 years were analyzed: sex, underlying diseases such as hypertension (previously known patient being treated with antihypertensive medications or blood pressure over 140/90 $\mathrm{mm} \mathrm{Hg}$ during nonacute phase) and diabetes mellitus (DM) (fasting glucose $>7 \mathrm{mmol} / \mathrm{L}$ or patient being treated with antidiabetic medication), smoking history (current or past), alcohol history, and other diseases such as history of ischemic stroke and cardiac diseases (heart failure, arrhythmia).

\section{Analysis of post-operative state and follow up}

Clinical outcome of each patient at 1 month after surgical clipping was assessed using Glasgow Outcome Scale (GOS) based on the following: GOS score of 5, no disability; GOS score of 4, moderate disability (i.e., no need for assistance in everyday life, employment is possible although it may require special equipment); GOS score of 3 , severe disability (i.e., severe injury with permanent need for help with daily living); GOS score of 2, persistent vegetative state; and GOS score of 1, death. Patients were divided into two groups according to their GOS scores: good outcome group (GOS score of 5) and poor outcome group (GOS score of 1 to 4). Small disability after surgical clipping of UIAs was considered unacceptable in this study. Therefore, GOS 4 was also considered a poor outcome after clipping of unruptured aneurysm.

\section{Statistical analysis}

All statistical analyses were performed with SPSS ver. 23.0 (IBM corporation, Armonk, NY, USA). Binary logistic regression analysis was performed to examine any independent association between groups. Odds ratio (ORs) and their $95 \%$ confidence intervals $(\mathrm{CIs})$ were estimated. Both multivariate and univariate analysis were performed. Data are expressed as mean \pm standard deviation (SD). Statistical significance was considered at $\mathrm{P} \leq 0.05$. Between-cohort comparisons for distributions of baseline characteristics were performed with Chi-squared test for categorical variables and Mann-Whitney test for continuous variables.

\section{RESULTS}

\section{Comparison of risk factors between the good outcome group and the poor outcome group}

Results of comparison for patient and aneurysmal characteristics 
between the good outcome group and the poor outcome groups are summarized in Table 1.

\section{Postoperative mortality and morbidity}

A total of 38 (76\%) patients achieved good outcome (GOS score of 5) at 1 month follow up. However, 12 (24\%) patients had poor outcome. Overall mortality rate was $1 \%$ and overall surgical morbidity rate was $24 \%$. One of 50 patients died after the operation within one month. The death was due to sepsis. Nine patients had GOS score of 4 at 1 month postoperatively. These patients showed third nerve palsy diplopia and short term memorial impairment. Two patients had GOS score of 2 or 3 . They showed hemiparesis and severe cognitive dysfunction.

\section{Patient characteristics}

A total of 50 patients with newly diagnosed aneurysms who underwent treatment for aneurysms were reviewed over a period of 10 years. Of the 38 patients in the good outcome group, 8 (21\%) were males while $30(79 \%)$ were females. Their average age was $69.5 \pm 3.8$ years. ( 65 to 78 year) Of the 12 patients in the poor outcome group, two (16\%) were males and 10 (84\%) were fe- males. Their mean age was $68.9 \pm 3.4$ years. (65 to 75 year) Age was not significantly $(\mathrm{p}=0.846)$ associated with surgical outcome. Sex did not show significant $(p=0.076)$ difference between the two groups either. A total of 40 patients had hypertension. However, the distribution of hypertension was not significantly $(\mathrm{p}=0.174)$ different between the good outcome group and the poor outcome group. Nine patients had DM. The distribution of DM was significantly ( $\mathrm{p}=0.023$ ) different between the two groups. The number of patients with history of drinking alcohol showed no significant $(\mathrm{p}=0.070)$ difference between the two groups. Smoking history also showed statistically significant $(\mathrm{p}=0.050)$ difference between the two groups.

\section{Aneurysms characteristics}

Mean neck size was $3.90 \pm 1.49 \mathrm{~mm}$ in the good outcome group, which was not significant $(\mathrm{p}=0.512)$ different from that $(4.47 \pm 2.00 \mathrm{~mm})$ of the poor outcome group. Mean height was not significantly different either between the two groups $(5.15 \pm$ $3.01 \mathrm{~mm}$ in the good outcome group vs. $6.70 \pm 4.12 \mathrm{~mm}$ in the poor outcome group, $\mathrm{p}=0.113)$. Mean width in the good outcome group group $(5.93 \pm 4.01 \mathrm{~mm})$ was higher than that in the

Table 1. Comparison of patient characteristics and aneurysmal characteristics between the good outcome group and the poor outcome group

\begin{tabular}{|c|c|c|c|}
\hline & Good outcome group (GOS 5) (38 patients) & Poor outcome Group (GOS 1-4) (12 patients) & p-value \\
\hline \multicolumn{4}{|l|}{ Age } \\
\hline Mean - yr & $69.5 \pm 3.8$ & $68.9 \pm 3.4$ & 0.846 \\
\hline Hypertension (\%) & $30(79)$ & $10(84)$ & 0.174 \\
\hline Diabetes mellitus (\%) & $6(15)$ & $3(25)$ & 0.023 \\
\hline Ischemic stroke (\%) & $4(10)$ & $1(8)$ & 0.548 \\
\hline Smoke history (\%) & $4(10)$ & $3(25)$ & 0.050 \\
\hline Alcohol (\%) & $4(10)$ & $1(8)$ & 0.070 \\
\hline Others & $6(15)$ & $4(33)$ & 0.412 \\
\hline \multicolumn{4}{|l|}{ Size of aneurysms } \\
\hline \multicolumn{4}{|l|}{ Mean \pm SD - mm } \\
\hline Maximum diameter & $6.32 \pm 3.93$ & $7.34 \pm 3.95$ & 0.254 \\
\hline Aspect ratio & $1.37 \pm 0.64$ & $1.59 \pm 0.90$ & 0.474 \\
\hline \multicolumn{4}{|l|}{ Location of aneurysms (\%) } \\
\hline Anterior communicating artery (\%) & $13(33)$ & $5(41)$ & 1.000 \\
\hline Posterior communicating artery (\%) & $3(7)$ & $3(25)$ & 0.323 \\
\hline Middle cerebral artery (\%) & $20(51)$ & $4(33)$ & 0.213 \\
\hline Internal carotid artery $(\%)$ & $2(5)$ & $0(0)$ & 1.000 \\
\hline Daughter sac (\%) & $7(17)$ & $5(41)$ & 0.263 \\
\hline
\end{tabular}

Bold Indicates statistically significant difference of $\mathbf{p}<0.05$. 
poor outcome group $(5.73 \pm 2.54 \mathrm{~mm})$. However, the difference was not statistically significant $(\mathrm{p}=0.880)$. The maximum diameter $(6.32 \pm 3.93 \mathrm{~mm}$ in the good outcome group vs. $7.34 \pm 3.95$ $\mathrm{mm}$ in the poor outcome group, $\mathrm{p}=0.254)$ or aspect ratio $(1.37$ \pm 0.64 in the good outcome group vs. $1.59 \pm 0.90$ in the poor outcome group, $\mathrm{p}=0.474$ ) was not also significantly different between the two groups either. The most common location of aneurysms in the good outcome group was MCA (51\%, 20 patients). It was $\mathrm{ACoA}$ (35\%, 5 patients) in the poor outcome group. The distribution of UIA was not significantly different in any location. A total of 12 patients had daughter sac, including 7 patients in the good outcome group and 5 patients in the poor outcome group. The ratio of patients with daughter sac was not significantly $(p=0.263)$ different between the two groups.

\section{Association between risk factors and poor outcome after aneurysmal clipping}

Results of logistic regression analysis of associations between risk factors and surgical outcome are shown in Table 2, 3. No statistically significant factors were found in univariate analysis. Known risk factors for surgical outcome for the elderly such as smoking (OR:1.419, $\mathrm{p}=0.300)$, hypertension (OR: $1.333, \mathrm{p}=0.682$ ),

Table 2. Univariate analysis between the good outcome group and the poor outcome group

\begin{tabular}{|c|c|c|c|}
\hline \multirow{2}{*}{ Clinical characteristics } & \multicolumn{3}{|c|}{ Univariate analysis } \\
\hline & OR & 95\% CI for OR (Lower-upper) & p-value \\
\hline Age & 0.954 & $0.802-1.135$ & 0.594 \\
\hline No. of females & 1.548 & $0.287-8.364$ & 0.611 \\
\hline Hypertension(Positive) & 1.333 & $0.336-5.290$ & 0.682 \\
\hline Diabetes mellitus(Positive) & 1.667 & $0.142-3.125$ & 0.607 \\
\hline Smoke history(Positive) & 1.419 & $0.081-2.167$ & 0.3 \\
\hline Alcohol user(Positive) & 1.486 & $0.152-14.553$ & 0.734 \\
\hline \multicolumn{4}{|l|}{ Size of aneurysms } \\
\hline \multicolumn{4}{|l|}{ Mean \pm SD $(\mathrm{mm})$} \\
\hline Neck & 1.228 & $0.854-1.766$ & 0.267 \\
\hline Height & 1.136 & $0.953-1.354$ & 0.156 \\
\hline Width & 0.984 & $0.824-1.175$ & 0.858 \\
\hline Maximum diameter & 1.062 & $0.919-1.228$ & 0.414 \\
\hline Aspect ratio (\%) & 1.527 & $0.670-3.478$ & 0.313 \\
\hline \multicolumn{4}{|l|}{ Location of aneurysms(Positive) } \\
\hline Anterior communicating artery & 0.9 & $0.250-3.237$ & 0.872 \\
\hline Posterior communicating artery & 0.306 & $0.054-1.736$ & 0.181 \\
\hline Middle cerebral artery bifurcation & 2.632 & $0.704-9.838$ & 0.15 \\
\hline Internal carotid artery & 6.112 & $0.000-99.99$ & 0.999 \\
\hline Daughter sac(Positive) & 2.54 & $0.684-9.947$ & 0.181 \\
\hline
\end{tabular}

OR: Odds ratio, CI: Confidence interval.

Table 3. Multivariate analysis between the good outcome group and the poor outcome group

\begin{tabular}{lccc}
\hline \multirow{2}{*}{ Clinical characteristics } & \multicolumn{3}{c}{ Multivariate analysis } \\
\cline { 2 - 4 } Neck & OR & $95 \%$ CI for OR (Lower-upper) & p-value \\
Width & 3.467 & $1.183-10.161$ & $\mathbf{0 . 0 2 3}$ \\
Diabetes mellitus & 0.511 & $0.262-0.994$ & $\mathbf{0 . 0 4 8}$ \\
Smoke & 1.048 & $1.004-1.655$ & $\mathbf{0 . 0 2 3}$ \\
Alcohol & 1.091 & $1.008-1.997$ & $\mathbf{0 . 0 5 0}$ \\
Aspect ratio & 92.97 & $0.695-12443.9$ & 0.070 \\
Shape(Daughter sac; (Positive) & 9.050 & $1.831-44.736$ & $\mathbf{0 . 0 0 7}$ \\
Posterior communicating artery & 6.788 & $0.805-57.232$ & 0.078 \\
\end{tabular}

OR: Odds ratio, CI: Confidence interval, Bold Indicates statistically significant difference of $\mathbf{p}<\mathbf{0 . 0 5}$. 
posterior circulation (OR: 0.306, $\mathrm{p}=0.181$ ), daughter sac (OR: $2.540, \mathrm{p}=0.181$ ), and large size aneurysms (height, OR: 1.136, $\mathrm{p}=$ 0.156; width, OR: $0.984, \mathrm{p}=0.858$ ) showed no significant association with surgical outcome. However, multivariate analysis revealed that large neck size of aneurysm (OR:3.467, $p=0.023$ ), small width (OR: $0.511, p=0.024)$, large aspect ratio (OR: 9.050, $p=0.007$ ), $\mathrm{DM}$ (OR: 1.048, $\mathrm{p}=0.023$ ), and smoking history (OR: 1.091, $\mathrm{p}=$ 0.050 ) were significantly associated with poor outcome.

\section{DISCUSSION}

Results of this study revealed that smoke history and DM were significantly different between the good outcome group and the poor outcome group. This is because patients with a smoking and DM history account for more ratio in poor outcome group than good outcome group (smoking history: 4 (10\%) patients in the good outcome group vs. 3 (21\%) patients in the poor outcome group, $\mathrm{p}=0.050$; DM: 6 (15\%) patients in the good outcome group vs. $3(21 \%)$ patients in the poor outcome group, $\mathrm{p}=0.023$ ). Both smoking and DM had significant association with poor prognosis after surgery.

In multivariate analysis, large neck size, small width, large aspect ratio, DM, and smoking were independently associated with poor outcome group. Smoking is generally known as a a risk factor of poor outcome $\mathrm{e}^{17,21)}$. Smoking can cause inflammatory reaction and increase the risk of aneurysms rupture ${ }^{11,16)}$. Pneumonia is very common in postoperative elderly patients. It occurs more frequently in smokers than that in non-smokers. It is difficult to treat pneumonia in smokers. In addition, nicotine can impair vascular elasticity and increase its fragility. It reduces adaptation to circulation changes, thus complicating certain procedures such as catheter insertion $^{24)}$. In our study, smokers had worse prognosis than non-smokers. DM is a controversial risk factor for poor outcome. Some studies have found that DM is a risk factor of poor outcome ${ }^{2,8)}$. On the contrary, it is a statistically insignificant factor in other studies ${ }^{20}$. In our study, people with DM were found to have worse prognosis after aneurysmal clipping than those without DM.

When treating aneurysms in elderly patients, multiple factors including the presence of hypertension, stroke, congestive heart disease, size and ruptured aneurysms have been found to contribute to poor outcome $\mathrm{e}^{18,23)}$. Hypertension is a controversial risk factor for poor outcome of elderly patients. It is a significant risk factor in one study, but an insignificant risk factor in other studies ${ }^{7,10,12}$. In our study, the effect of hypertension on prognosis was not statistically significant.

Previous studies have revealed that the rupture risk is increased almost linearly with increasing age of patients with intracranial an- eurysms ${ }^{6,13)}$. However, there was no increasing poor outcome ratio according to age in the present study.

Alcohol has been reported to be a risk factor for poor outcome in the elderly ${ }^{5}$. However, it was not a risk factor for poor outcome in the present study. It has been reported that aneurysm size plays an important role in determining the outcome of $\mathrm{SAH}$ patients. Large aneurysms are usually accompanied by broad neck, perforating vessels, and intraluminal thrombosis, thereby increasing operative risk ${ }^{2,24}$. It has been reported that an aneurysm of about $7 \mathrm{~mm}$ or more than $4 \mathrm{~mm}$ will increases the risk of rupture ${ }^{9,4)}$. Our results also showed that large neck size and small width had significant association with poor outcome. However, height was not a significant risk factor for poor outcome in our study. In addition, our results revealed that higher aspect ratio had significant association with poor outcome. It is also known that the risk of rupture is high when there is a daughter $\mathrm{sac}^{4}$. However, our study revealed that the existence of daughter sac did not have significant difference between the two groups.

Our study has some limitations. First, the data were retrospectively collected at a single center whereas surgical clipping was performed by multiple surgeons. Surgical skill might be different among the surgeons. Second, the number of patients enrolled in this study was relatively small. Thus, there might be statistical error in some analysis. Third, although surgical approach for the posterior circulation is known to be more difficult than the anterior circulation, there was no surgical case of posterior circulation in this study. Thus, future prospective studies should be performed with larger sample sizes and more concise evaluation to make better decisions on treatment for elderly patients with UIAs.

\section{CONCLUSION}

The decision to treat an UIA in an elderly patient is difficult because there are many considerations before surgery. Treatment strategy should consider not only the risk of rupture but also expected patient status after the surgery. In this study, patient factors as well as aneurysmal characteristics were associated with poor outcome after aneurysm clipping in elderly patients.

\section{NOTES}

\section{Conflict of Interest}

No potential conflict of interest relevant to this article was reported.

\section{Acknowledgements}

The authors have no financial conflicts of interest. 


\section{REFERENCES}

1. Barker FG 2nd, Amin-Hanjani S, Butler WE, Hoh BL, Rabinov JD, Pryor JC, et al. Age-dependent differences in short-term outcome after surgical or endovascular treatment of unruptured intracranial aneurysms in the United States, 1996-2000. Neurosurg 2004;54:18-30.

2. Chernyshev OY, Bir SC, Maiti TK, Patra DP, Liendo C, Cuellar $\mathrm{H}$, et al. Changing paradigm in the management of elderly patients with intracranial aneurysms: An institutional review. J Clin Neurosci 2017;43:94-102.

3. Connolly ES Jr, Rabinstein AA, Carhuapoma JR, Derdeyn CP, Dion J, Higashida RT, et al. Guidelines for the management of aneurysmal subarachnoid hemorrhage: a guideline for healthcare professionals from the American Heart Association/american Stroke Association. Stroke 2012;43:1711-1737.

4. Seo DH, Kang HS, Kim DW, Park SQ, Song Y, Sheen SH, et al. Guidelines for the Management of Unruptured Intracranial Aneurysm. Kor J Cerebrovascul Surg 2011;13:279-290.

5. Feigin VL, Rinkel GJ, Lawes CM, Algra A, Bennett DA, van Gijn J, et al. Risk factors for subarachnoid hemorrhage: an updated systematic review of epidemiological studies. Stroke 2005;36:2773-2780.

6. Horiuchi T, Tsutsumi K, Ito K, Hongo K. Results of clipping surgery for aneurysmal subarachnoid hemorrhage in the ninth and tenth decades of life. J Clin Neurosci 2014;21:1567-1569.

7. Inagawa T. Risk factors for the formation and rupture of intracranial saccular aneurysms in Shimane, Japan. World Neurosurg 2010;73:155-164.

8. Inagawa T, Hirano A. Ruptured intracranial aneurysms: an autopsy study of 133 patients. Surg Neurol 1990;33:117-123.

9. International Study of Unruptured Intracranial Aneurysms Investigators. Unruptured intracranial aneurysms--risk of rupture and risks of surgical intervention. N Engl J Med 1998;339: 1725-1733.

10. Investigators UJ, Morita A, Kirino T, Hashi K, Aoki N, Fukuhara $\mathrm{S}$, et al. The natural course of unruptured cerebral aneurysms in a Japanese cohort. N Engl J Med 2012;366:2474-2482.

11. Jayaraman T, Paget A, Shin YS, Li X, Mayer J, Chaudhry H, et al. TNF-alpha-mediated inflammation in cerebral aneurysms: a potential link to growth and rupture. Vasc Health Risk Manag 2008;4:805-817.

12. Juvela S, Poussa K, Lehto H, Porras M. Natural history of unruptured intracranial aneurysms: a long-term follow-up study. Stroke 2013;44:2414-2421.

13. Lanzino G, Kassell NF, Germanson TP, Kongable GL, Truskowski LL, Torner JC, et al. Age and outcome after aneurysmal subarachnoid hemorrhage: why do older patients fare worse? J Neurosurg 1996;85:410-418.

14. Matsukawa H, Kamiyama H, Tsuboi T, Noda K, Ota N, Miyata $\mathrm{S}$, et al. Is Age a Risk Factor for Poor Outcome of Surgical Treatment of Unruptured Intracranial Aneurysms? World Neurosurg 2016;94:222-228.

15. Qureshi AI, Suri MF, Nasar A, Kirmani JF, Divani AA, He W, et al. Trends in hospitalization and mortality for subarachnoid hemorrhage and unruptured aneurysms in the United States. Neurosurgery 2005;57:1-8.

16. Rudolph TK, Rudolph V, Baldus S. Contribution of myeloperoxidase to smoking-dependent vascular inflammation. Proc Am Thorac Soc 2008;5:820-823.

17. Sedat J, Dib M, Lonjon M, Litrico S, Von Langsdorf D, Fontaine D, et al. Endovascular treatment of ruptured intracranial aneurysms in patients aged 65 years and older: follow-up of 52 patients after 1 year. Stroke 2002;33:2620-2625.

18. Taylor CL, Yuan Z, Selman WR, Ratcheson RA, Rimm AA. Cerebral arterial aneurysm formation and rupture in 20,767 elderly patients: hypertension and other risk factors. J Neurosurg $1995 ; 83: 812-819$.

19. Thompson BG, Brown RD, Amin-Hanjani S, Broderick JP, Cockroft KM, Connolly ES, et al. Guidelines for the Management of Patients With Unruptured Intracranial Aneurysms: A Guideline for Healthcare Professionals From the American Heart Association/American Stroke Association. Stroke 2015;46:2368-2400.

20. Vlak MH, Rinkel GJ, Greebe P, Algra A. Risk of rupture of an intracranial aneurysm based on patient characteristics: a case-control study. Stroke 2013;44:1256-1259.

21. Vlak MHM, Algra A, Brandenburg R, Rinkel GJE. Prevalence of unruptured intracranial aneurysms, with emphasis on sex, age, comorbidity, country, and time period: a systematic review and meta-analysis. Lancet Neurology 2011;10:626- 636.

22. Wermer MJ, van der Schaaf IC, Algra A, Rinkel GJ. Risk of rupture of unruptured intracranial aneurysms in relation to patient and aneurysm characteristics: an updated meta-analysis. Stroke 2007;38:1404-1410.

23. Wiebers DO, Whisnant JP, Huston J 3rd, Meissner I, Brown RD Jr, Piepgras DG, et al. Unruptured intracranial aneurysms: natural history, clinical outcome, and risks of surgical and endovascular treatment. Lancet 2003;362:103-110.

24. Yue Q, Liu Y, Leng B, Xu B, Gu Y, Chen L, et al. A Prognostic Model for Early Post-Treatment Outcome of Elderly Patients With Aneurysmal Subarachnoid Hemorrhage. World Neurosurg 2016;95:253-261. 